vol.6. No. 2 - 2019

\title{
IMPACT OF IMPLEMENTING JOURNAL CLUB ON DEVELOPING KNOWLEDGE OF ACADEMIC STAFF MEMBERS ABOUT EVIDENCE-BASED PRACTICE APPROACH
}

\author{
${ }^{1}$ Eman Samy, ${ }^{2}$ Amel Ibrahim Ahmed, ${ }^{3}$ Samia Mahmoud Abd El-Mouty, \\ ${ }^{4}$ Rasha Abbas Mohamed
}

${ }^{1}$ Assistant Lecturer, Community Health Nursing, Faculty of Nursing, Mansoura University, Egypt.

${ }^{2}$ Assistant Professor, Community Health Nursing, Faculty of Nursing, Mansoura University, Egypt. ${ }^{3}$ Assistant Professor, Community Health Nursing, Faculty of Nursing, Mansoura University, Egypt. ${ }^{4}$ Lecturer, Community Health Nursing, Faculty of Nursing, Mansoura University, Egypt.

\begin{abstract}
Background: Evidence-based practice (EBP) is one of the main professional competencies for healthcare professionals and a priority for the nursing curriculum. Nurse educators have the accountability to train the future nurses which requires them to have adequate knowledge in EBP. Journal clubs (JC) have been recommended as teaching or learning strategies that promote knowledge, attitudes, motivation and competencies essential for EBP. Aim: To assess the impact of implementing a journal club on developing academic staff members' EBP knowledge. Method: A quasi-experimental research design was conducted among (32) academic staff members at the Community Health Nursing department, Faculty of Nursing, Mansoura University, Egypt. Results: It was observed that $(93.8 \%)$ of them were females, $(71.9 \%)$ had a bachelor degree in nursing and were clinical demonstrators. Half of them (50\%) worked for less than five years with a mean of $1.72 \pm .81$ years. In relation to knowledge about the concept and five steps of EBP, total knowledge score revealed that $(9.4 \%)$ of the academic staff members showed good score level of knowledge with a mean of $47.21 \pm 31.31$ marks during pre (JC) sessions. However, $(90.6 \%)$ of them showed good score level of knowledge with a mean of $131.90 \pm 13.02$ marks and $131.68 \pm 12.06$ marks during immediate post implementation of (JC) and after six months follow up period respectively. Conclusion: The study concluded that the participation in the EBP journal club (JC) leads to significant improvements in EBP knowledge. Recommendations: It was recommended to promote the journal club process and integrate it into the undergraduate courses and nursing education programs then evaluate its utility in facilitating evidence-based practice over time. Encourage nurse educators to include a monthly journal club on their workplace for professional development.
\end{abstract}

Keywords: Nursing educators; Evidence-based practice; Journal club.

\section{Introduction}

Evidence-based practice (EBP) is defined as the conscientious, explicit and judicious use of theory-derived, researchbased information combined with clinical expertise while considering resources, individual needs and preferences to make clinical decisions [1].
Finding appropriate evidence requires asking a precise, searchable and answerable clinical question followed by methodically and systematically searching the medical, nursing and allied health databases to acquire the best available research evidence [2]. 
Evaluating the quality of evidence is the next step in EBP and involves appraising the acquired research for its reliability and validity. Next, the existing research evidence is considered useful when implemented into usual practice. Finally, it is necessary to evaluate the effectiveness of the undertaken decision or practice changes based on outcomes. Ideally, dissemination of the process and outcomes is the final step in EBP [3].

Globally, evidence-based practice (EBP) has identified as a major healthcare initiative [4]. It constitutes one of the professional competencies of healthcare professionals and is among the priorities of nursing education programs. In order to expedite the transfer of research findings to clinical practice, it is essential for nurses to acquire sufficient knowledge, skills and have strong belief in the crucial role of EBP in clinical settings [5].

Nursing educators are responsible for training the future nurses, so their participation by integrating the EBP into clinical education will improve healthcare outcomes [6]. Consequently, they must involve themselves in clinical issues and approximate clinical, educational, and research activities through teaching EBP to students and nurses. These require nursing educators to have sufficient knowledge and skills in EBP before involvement in this form of practice [5].

Nursing educator's competency is one of the most important factors in the learning process. To be able to deliver EBP properly, nursing educators must have the adequate knowledge of setting relevant clinical questions, seeking and evaluating different types of knowledge and making decisions based on the evidence. There is a lack of studies focusing on the knowledge of nursing educators of EBP approach [7]. Journal clubs (JC) have been recommended as teaching or learning strategies that promote the knowledge, attitudes, motivation and competencies essential for producing evidence-based care [8].

Journal club (JC) is defined as a group of participants who meet regularly in order to discuss research articles in the current literature. Today, it is recognized as an international teaching tool in the academic setting and time-honored tradition for learning the latest in research and teaching critical appraisal skills [9].

Journal clubs have been implemented for helping both healthcare professionals and students to develop their knowledge and skills of setting clinical questions, searching, finding, discussing and evaluating scientific knowledge [10]. JC aids in understanding of scientific research. It also leads to improvement in clinical practice through encouragement of discussion and using research for keeping up-to-date with the latest developments [11].

The aim of the study:

To assess the impact of implementing a journal club on developing academic staff members' EBP knowledge.

\section{Subjects and Method}

Design:

A quasi-experimental design was utilized to carry out this study.

Setting:

The study was carried out at the Community Health Nursing departmentFaculty of Nursing- Mansoura University, Egypt.

\section{Subjects and sampling:-}

Subjects:

All available academic nursing staff members (32) at Community Health Nursing department which involved: twenty-two demonstrators, six assistant lecturers and four lecturers.

\section{Sampling technique:}

Purposive sample technique was used to recruit the study subjects.

\section{Tools for data collection:}

After reviewing the relevant literature, two tools were designed by the researcher in the study for collecting data. 
Tool I: A structured questionnaire was used to assess demographic and academic data of the staff members including age, sex, educational level, academic ranking, certified specialist, teaching role, research activities, and years of experience in their academic setting.

Tool II:- A self-administered structured questionnaire was used to assess the academic staff members' knowledge regarding evidence-based practice (EBP) including definition, importance and benefits of evidence-based practice. In addition to steps of EBP, which include formulating the clinical question; searching efficiently for the best available evidence; critically appraising the evidence; applying and disseminating the evidence.

The questions were classified into six categories, in (148) questions. Each knowledge question was given one mark for the correct answer. The knowledge' questions were divided into five questions for concept of evidence based practice category, fifty two questions for asking answerable and searchable question category, thirty one questions for acquiring research category, thirty nine questions for appraising research category, eleven questions for applying and disseminating evidence category and ten questions for critically appraised topics category.

The total knowledge score was categorized into three levels. Poor level $=$ scores less than $50 \%$ of total scores $(<74$ marks). Fair level $=$ scores $50 \%$ to $<75 \%$ of total scores (74 to less than 111 marks) and good level $=$ scores more than $75 \%$ of total scores (more than 111 marks).

\section{Method:}

This study was accomplished throughout two main phases:

\section{Phase I: Preparatory phase}

1- Administrative process and Ethical considerations.

- An official permission was obtained from the Faculty of Nursing, Mansoura University and
Community Health Nursing department after clarifying the aim of the study.

- An ethical approval was obtained from the Faculty of Nursing Research Ethics Committee (FNREC), Mansoura University to conduct the study.

- Verbal informed consent was obtained from the academic staff members after clarifying the aim of the study and ensuring confidentiality of data. Participants were also informed about their right to withdraw from the study at anytime without giving any reason.

\section{2- Developing of the study tools:}

Tools were developed by the researcher based on reviewing the relevant local and international literature. Validity of the developed tools was tested for: content validity by submitting the tools to a jury of five experts in the field of "Community Health Nursing and evidence-based practice". Face validity was tested by conducting a pilot study on $10 \%$ of study sample $(\mathrm{n}=3)$ who were not included in the study. Based on the collected data, the necessary modifications were done, some questions were added, and others were clarified or omitted.

\section{Phase II: Operational phase}

Stage 1: Initial data collection

All academic staff members completed the pre-JC sessions selfadministered structured questionnaire. It was designed for determining the academic staff members' demographic, academic data, in addition to their knowledge regarding the five steps of EBP.

Stage 2: Planning for implementing journal club sessions.

1. A structured JC club format was planned to be utilized throughout this study. A clear aim, specific objectives and JC contents were defined before implementing JC sessions. The sessions' number, duration, day, time, 
location was predetermined. JC session plan were set before it's implementation.

2. A pilot study was conducted on three academic staff members in Community Health Nursing department who were experts in evidence-based practice approach to evaluate the clarity, applicability, and reliability of the journal club session plan and estimate the approximate time required for implementing these sessions. Also, it helped in figuring out the limitations and problems that might also occur at some stage in the real implementation of journal club sessions. Accordingly, the necessary modifications were done.

\section{Stage 3: Implementing journal clubs}

\section{sessions.}

1. The journal club sessions were composed of eleven sessions focusing on developing the academic staff members' knowledge of steps of evidence-based practice approach. The five steps of evidence were composed of stating searchable questions, tracking the evidence, appraising the evidence and applying and disseminating the evidence.

2. On the first day of the journal club session, the academic staff members identified the meaning of EBP, benefits, steps and how to use it in clinical practice. Then the researcher divided the academic staff members into small groups, each group was composed of 5-6 members. One facilitator was assigned from each group to collaborate in distributing the activities among the group.

3. At the sessions, the academic staff members identified the PICO trend (P: population or patient; I: intervention; $\mathrm{C}$ : comparison; and $\mathrm{O}$ : outcome), types of questions, hierarchies of evidence, types of study design and best study to answer each type of the question.
4. Illustrations of the different sources of biomedical information databases, their relevance and location, with detailed description of how to design effective search strategies for finding valid evidence was given at the next sessions.

5. The highest numbers of sessions were dedicated to explain the critical appraisal step, common statistical terms, basic criteria affecting the internal and external validity of primary and secondary researches and how to determine the level and grade of evidence.

6. The last session ended with explanation of evidence table which describes the main information extracted from appraised scientific article, methods of evidence dissemination including critically appraised topics CATs summary. Illustrated handout about EBP distributed after implementing each (JC) session as a reference.

Stage 4: Evaluating journal club sessions.

There were eight periods of data collection: pre-JC sessions, immediate post-JC sessions and six follow up periods occurred monthly for six months to assess the level of improvement in their knowledge after the completion of (JC) sessions.

\section{Statistical analysis:}

Data was sorted, coded, organized, categorized and then transferred into especially designed formats. Analysis performed using SPSS (Stands for Statistical Product and Service Solutions) version 21. Categorical variables were described using number and percent. Continuous variables were presented as mean \pm SD (standard deviation). Repeated measured analysis of variance (RMANOVA) was used to compare means in different follow up durations. A statistical test with a $\mathrm{p}$ value $<0.05$ was considered statistically significant. 


\section{Results:}

Table (1) reflects the distribution of the academic staff members according to their demographic and academic data. The mean age of the academic staff members was $29.78 \pm 5.44$ years. It was observed that most of them $(93.8 \%)$ were females, $(71.9 \%)$ had bachelor degree in nursing and were clinical demonstrator. Regarding years of experience, half of them $(50 \%)$ worked less than five years with a mean of $1.72 \pm .81$ years. In relation to their role in teaching, only $(12.5 \%)$ taught theoretical content of the course. While, $(87.5 \%)$ taught the clinical content. Concerning research activities, $(68.8 \%)$ prepared working on thesis, (3.1\%) and (6.2\%) already have finished their thesis and prepared for writing research their paper respectively.

Table (2) presents the distribution of the academic staff members according to their history of prior training in evidence-based practice (EBP). It was found that, (56.2\%) of them previously attended training session(s) on searching. While, (15.6\%) attended session(s) in critical appraisal. Regarding number of those sessions, the same result $(28.1 \%)$ was found for once and twice time respectively.

Table (3) illustrates distribution of the academic staff members according to their scores level of knowledge regarding (EBP) pre, immediate post and for six months follow up the implementation of journal club (JC) sessions. It was noted that, $(25 \%)$ of them showed good score level of knowledge with a mean of $2.62 \pm 1.18$ marks related to concept of evidence-based practice during pre (JC) session. However, $(90.6 \%)$ and $(87.5 \%)$ of them showed good score level of knowledge with a mean of $4.47 \pm 0.76$ marks and $4.37 \pm 0.79$ marks during immediate post and after six months follow up period respectively. The difference was significant between pre, post and follow up test regarding the previous item $(\mathrm{F}=18.22, \mathrm{P}=0.000)$.

In relation to asking answerable and searchable questions sessions, $(15.6 \%)$ of them showed good score level of knowledge with a mean of $21.90 \pm 11.99$ marks during pre (JC) session. However, (96.9\%) showed good score level of knowledge during immediate post and after six months follow up period with a mean of $48.62 \pm 3.28$ marks and $48.43 \pm 3.34$ marks respectively. The difference was significant between pre, post and follow up test regarding the previous item $(\mathrm{F}=101.85, \mathrm{P}=0.000)$.

Concerning acquiring research sessions, (12.5\%) of them showed good score level of knowledge with a mean of $8.97 \pm 4.09$ marks during pre (JC) session. However, (81.2\%) and (84.4\%) showed good score level of knowledge with a mean of $27.41 \pm 3.35$ marks and $27.12 \pm 3.22$ marks during immediate post and after six months follow up period respectively. The difference was significant between pre, post and follow up test regarding the previous item $(\mathrm{F}=75.38, \mathrm{P}=0.000)$.

As regards to appraising research sessions, $(87.5 \%)$ of them showed poor score level of knowledge with a mean of $9.00 \pm 4.61$ marks during pre (JC) session. However, (78.1\%) and (81.2\%) showed good score level of knowledge with a mean of $33.65 \pm 5.57$ marks and 33.84 \pm 5.19 marks during immediate post and after six months follow up period respectively. The difference was significant between pre, post and follow up test regarding the previous item $(\mathrm{F}=70.35, \mathrm{P}=0.000)$.

Regarding applying and disseminating evidence session, (12.5\%) of them showed good score level of knowledge with a mean of $3.53 \pm 3.22$ marks during pre (JC) session. However, $(90.6 \%)$ and $(87.5 \%)$ showed good score level of knowledge with a mean of $10.37 \pm 1.73$ marks and $10.81 \pm 2.16$ marks during immediate post and after six months follow up period respectively. The 
difference was significant between pre, post and follow up test regarding the previous item $(\mathrm{F}=42.54, \mathrm{P}=0.000)$.

Concerning critically appraised topics session, $(9.4 \%)$ of them showed good score level of knowledge with a mean of $1.18 \pm 0.70$ marks pre (JC) session. However, (68.8\%) showed good score level of knowledge with a mean of $7.37 \pm 3.36$ marks and $7.09 \pm 3.42$ marks immediate post and after six months follow up period respectively. The difference was significant between pre, post and follow up test regarding the previous item $(\mathrm{F}=12.39, \mathrm{P}=0.000)$.

Overall, total knowledge score revealed that $(9.4 \%)$ of the academic staff members showed good score level of knowledge with a mean of 47.21 \pm 31.31 marks pre (JC) sessions in relation to concept of evidence-based practice, asking answerable and searchable questions, acquiring research, appraising research, applying and disseminating evidence and critically appraised topics. However, $(90.6 \%)$ of them showed good score level of knowledge with a mean of $131.90 \pm 13.02$ marks and 131.68 \pm 12.06 marks during immediate post and after six months follow up period respectively. The difference was significant between pre, post and follow up test regarding the previous item $(\mathrm{F}=109.39, \mathrm{P}=0.000)$.

Discussion:

Achieving the highest quality patient outcomes and optimizing the use of healthcare resources should be the goal of every healthcare system, whether in developed or developing countries [12]. In the developed countries, training for healthcare specialist to put evidence into practice is widely available and regularly evaluated [13]. However, in developing countries, evidence-based practice is in its infancy. Whilst the standards of EBP are particularly relevant in developing countries to underpin health policy and healthcare delivery, the growth of EBP has been slower in developing countries. Some reasons for the slow growth are lack of knowledge of EBP and limited research capacity [14].

Educating nursing students with core knowledge associated EBP may be a powerful strategy to increase their self belief and, in turn, affect their future use of evidence in their nursing practice to deliver fantastic care that will have an impact on patient health [2]. Considering the novelty of the ideas of EBP in nursing education in Egypt, few nursing studies conducted about these issues. It is mentionable that nursing educators are need to be committed to the principles of EBP, provide resources, and create a supportive environment for its implementation [14]. However, there is a lack of studies focusing on the knowledge of nurse educators of EBP approach [7].

Journal clubs have been suggested as teaching or learning methods that promote the knowledge, attitudes, motivation and competences essential for evidence-based practice [10]. Accordingly, the aim of the current study is to assess the impact of implementing journal club on developing academic staff members' knowledge about evidence-based practice approach at Community Health Nursing department. This study aim is consistent with [15].

Regarding to prior training in EBP of the academic staff members, it was declared that, more than half of them attended previous course in evidence based-practice. This finding were not consistent with similar studies that assess the effect of a training program on evidence-based practice knowledge and skills and found that only $8.9 \%$ and $17.1 \%$ attended previous EBP courses [2].

The results of this study included significant improvement in EBP knowledge of the staff members who attended the journal club immediately after implementing JC and over a six months period of providing support and observation. Concerning the impact of 
journal club, the results revealed that there were high significant differences between academic staff members' knowledge before and after journal club implementation. The finding revealed that $(84.4 \%)$ of academic staff members showed poor score level with a mean of 47.21 \pm 31.31 marks before implementing (JC) sessions in relation to concept of evidence based practice, asking answerable and searchable questions, acquiring research, appraising research, applying and disseminating evidence and critically appraised topics. However, $(90.6 \%)$ of them showed good knowledge score level with a mean of $131.90 \pm 13.02$ marks and 131.68 \pm 12.06 marks immediately and six months after implementing (JC) sessions respectively.

The findings of the current study are consistent with other published researches that implemented JC format based on using the academic facilitator; critical appraisal based on groups and consistent use of critical appraisal tools. These studies found that structured JC format may maintain EBP knowledge and skills in allied health clinicians and facilitate their engagement $[15,16,17 \&$ 18]. The improvement in EBP knowledge could be expected due to the low knowledge scores pre- JC implementation, and the naïve EBP nature of the participants. The academic nursing staff who participated in this study had little prior and informal training in EBP, thus, it is expected that after undertaking $\mathrm{JC}$, their knowledge scores would improve.

\section{Conclusion:}

According to the findings of the current study, it can be concluded that journal club is considered an effective teaching and learning method of EBP approach for academic staff members. Participation in journal club (JC) leads to significant improvements in EBP knowledge to formulate questions, perform literature search, appraise critically, and apply best-evidence in clinical practice, which retained up to 6 months post- (JC) sessions.

\section{Recommendation:}

According to the findings and conclusions drawn from this study, the following recommendations are suggested: 1. A structured JC should be used to improve EBP knowledge at academic setting.

2. Integrate journal club process into the undergraduate courses and other nursing education programs with regular evaluation of its utility in facilitating evidence-based practice over time.

3. Nurse educators should be to include monthly journal club meeting for professional development on their workplace.

\section{Acknowledgements:}

We would like to thank all academic staff members who participated in the current study for their help and cooperation during the study period and appreciate the great efforts of the supervisors in this work. 
Eman Samy et. al.

Table (1): Distribution of the studied academic staff members according to their demographic and academic data:-

\begin{tabular}{|c|c|c|}
\hline Academic data & $\mathbf{N}(32)$ & $\%$ \\
\hline $\begin{array}{l}\text { Age/years } \\
<25 \text { years } \\
25-30 \text { years } \\
>30 \text { years }\end{array}$ & $\begin{array}{c}3 \\
16 \\
13\end{array}$ & $\begin{array}{c}9.40 \\
50 \\
40.6\end{array}$ \\
\hline$\square \pm$ SD & \multicolumn{2}{|c|}{$29.78 \pm 5.44$} \\
\hline $\begin{array}{l}\text { Sex } \\
\text { Female } \\
\text { Male } \\
\end{array}$ & $\begin{array}{c}30 \\
2 \\
\end{array}$ & $\begin{array}{c}93.8 \\
6.2 \\
\end{array}$ \\
\hline $\begin{array}{l}\text { Years of experience as a faculty member } \\
<5 \text { years } \\
5-<10 \text { years } \\
\geq 10 \text { years }\end{array}$ & $\begin{array}{c}16 \\
9 \\
7\end{array}$ & $\begin{array}{c}50 \\
28.1 \\
21.9\end{array}$ \\
\hline$\square \pm$ SD & \multicolumn{2}{|c|}{$1.72 \pm .81$} \\
\hline $\begin{array}{l}\text { Educational qualifications } \\
\text { Bachelor degree } \\
\text { Master degree } \\
\text { Doctorate degree }\end{array}$ & $\begin{array}{c}23 \\
5 \\
4\end{array}$ & $\begin{array}{l}71.9 \\
15.6 \\
12.5\end{array}$ \\
\hline $\begin{array}{l}\text { Academic ranking } \\
\text { Clinical demonstrator } \\
\text { Assistant lecturer } \\
\text { Lecturer }\end{array}$ & $\begin{array}{c}23 \\
5 \\
4\end{array}$ & $\begin{array}{l}71.9 \\
15.6 \\
12.5\end{array}$ \\
\hline $\begin{array}{l}\text { Teaching role } \\
\text { Clinical teaching } \\
\text { Teaching of theoretical content (lectures) }\end{array}$ & $\begin{array}{c}28 \\
4\end{array}$ & $\begin{array}{l}87.5 \\
12.5\end{array}$ \\
\hline $\begin{array}{l}\text { Research activities } \\
\text { Preparing a thesis / dissertation } \\
\text { Working on thesis / dissertation } \\
\text { Finishing thesis / dissertation } \\
\text { Preparing research paper } \\
\text { Preparing research paper and supervising thesis }\end{array}$ & $\begin{array}{l}22 \\
5 \\
1 \\
2 \\
2\end{array}$ & $\begin{array}{l}68.8 \\
15.6 \\
3.1 \\
6.2 \\
6.2\end{array}$ \\
\hline
\end{tabular}

Table (2): Distribution of the studied academic staff members according to their history prior training in evidence based-practice approach.

\begin{tabular}{|l|c|c|}
\hline \multicolumn{1}{|c|}{ Items } & $\mathbf{N = ( 3 2 )}$ & \% \\
\hline Past attendance of session(s) on searching & 18 & 56.2 \\
\hline Past attendance of session(s) in critical appraisal & 5 & 15.6 \\
\hline Number of prior training sessions in evidence- & & \\
based practice or research methodology & 14 & 43.8 \\
None & 9 & 28.1 \\
Once & 9 & 28.1 \\
Twice and more & & \\
\hline
\end{tabular}




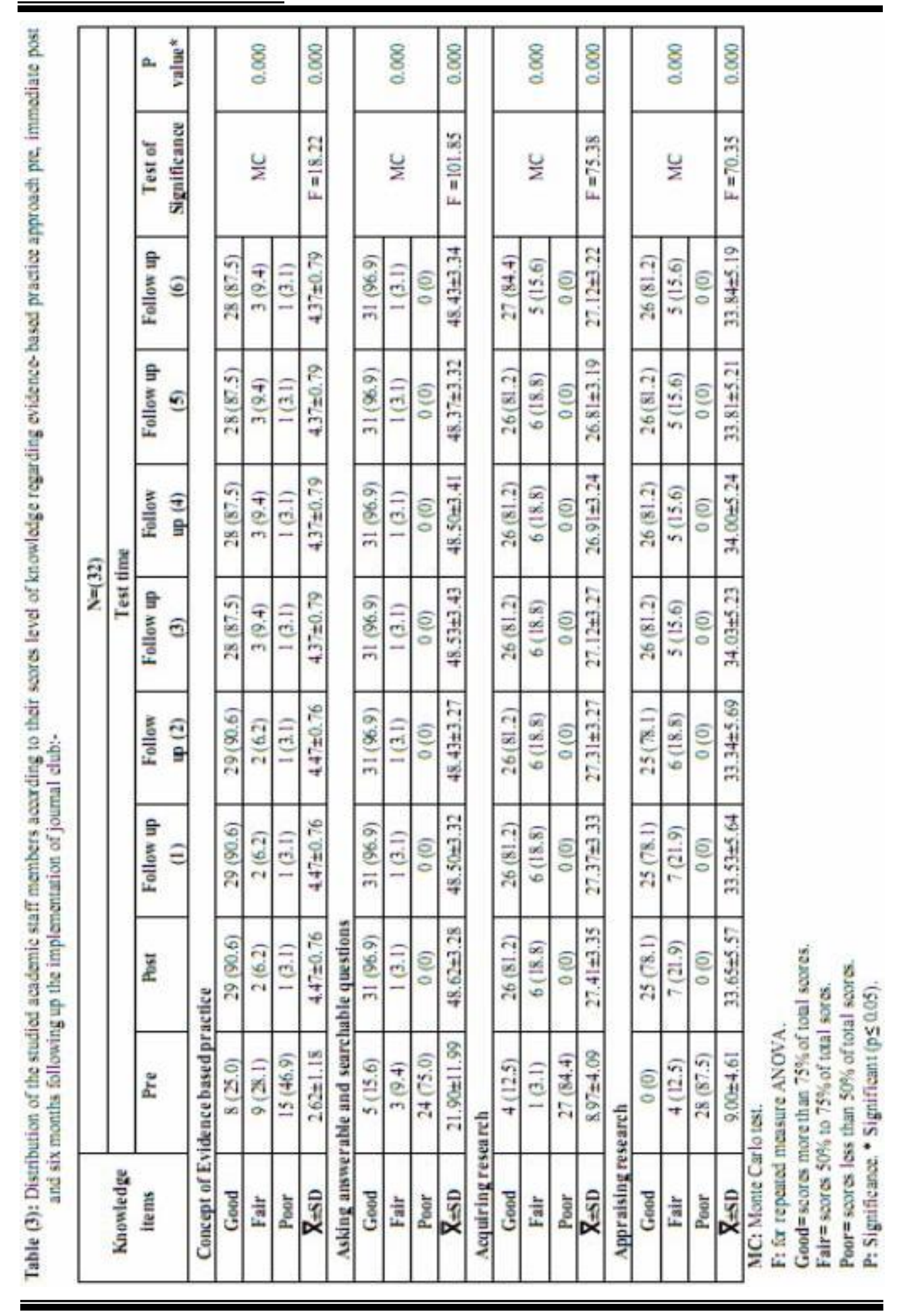


Eman Samy et. al.

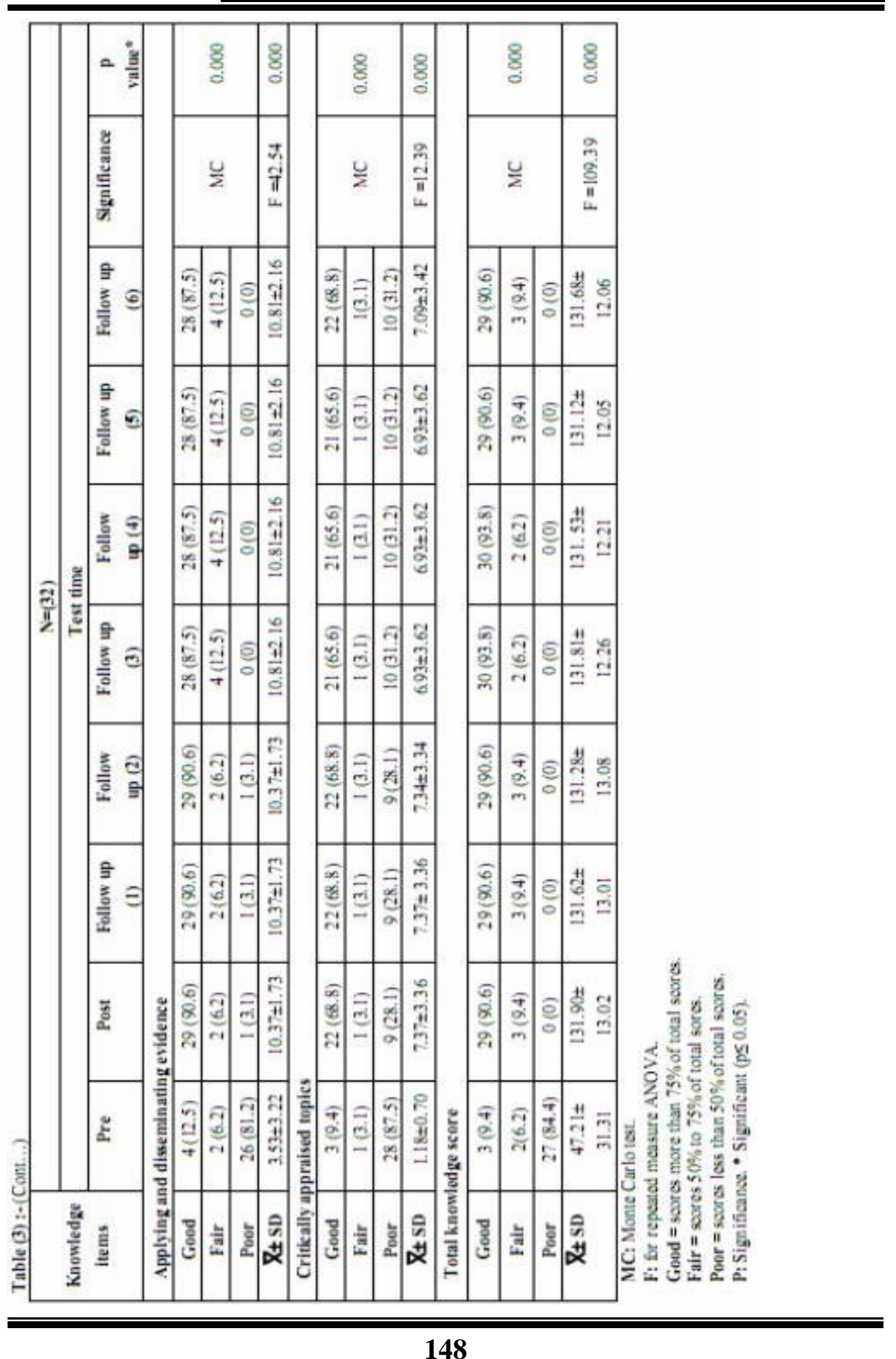




\section{References:}

1. Emanuel, V., Day, K., Diegnan, L., \& Pryce-Miller, M. (2011). Developing evidence based practice among students. Nursing Times, 107 (49/50), 21- 23.

2. El-Sayed, S. H., Hassona, F. M., \& Winkelman, C. (2014). Effect of a Training Program on Evidence Based Practice Profiles and Skills among Master Nursing Students. Zagazig Nursing Journal, 10(1), 1-18. doi:10.12816/0029300.

3. Melnyk, B. M., Fineout-Overholt, E., Stillwell, S. B., \& Williamson, K. M. (2010). Evidence-based practice: step by step: the seven steps of evidence-based practice. AJN The American Journal of Nursing, 110 (1), 51-55. doi:10.1097/01.naj. 0000366056.06605.d2.

4. Thiel, L., \& Ghosh, Y. (2008). Determining Registered Nurses Readiness for Evidence-Based Practice. Worldviews on EvidenceBased Nursing, 5(4), 182-192. doi:10.1111/j.1741-6787. 2008. 00137. x.

5. Mehrdad, N., Joolaee, S., Joulaee, A., Bahrani, N. (2012). Nursing faculties' knowledge and attitude on evidence-based practice. Iranian Journal of Nursing and Midwifery Research, 17(7), 506-511.

6. Penz, K. L., \& Bassendowski, S. L. (2006). Evidence-Based Nursing in Clinical Practice: Implications for Nurse Educators. The Journal of Continuing Education in Nursing, $37(6)$, 250-254. doi: 10.3928/ 00220124- 20061101-03.
7. Zeleníková, R., Beach, M., Ren, D., Wolff, E., \& Sherwood, P. (2014). Faculty Perception of the Effectiveness of EBP Courses for Graduate Nursing Students. Worldviews on Evidence-Based Nursing, 11(6), 401-413. doi:10.1111/wvn.12068.

8. Parhar, S., \& Gibson, J. (2016). Does participation in an undergraduate journal club make dental students more knowledgeable and confident in practicing evidencebased dentistry? European Journal of Dental Education, 21(4), 59-63. doi:10.1111/eje.12219.

9. Akhund, S., \& Kadir, M. M. (2006). Do community medicine residency trainees learn through journal club? An experience from a developing country. BMC Medical Education, 6(1), 1-6. doi:10.1186/1472-6920-643.

10. Laaksonen, C., Paltta, H., VonSchantz, M. L., Ylönen, M., Soini, T. (2013). Journal club as a method for nurses' and nursing students' collaborative learning: a descriptive study. Health Science Journal, 7(3), 285-292.

11. Muley, A., \& Lakhani, J. D. (2015). Evidence based vs traditional journal clubs: Time to switchover. The Journal of Medical Research, 1(1), 1317.

12. Dizon, J. M., Grimmer-Somers, K., \& Kumar, S. (2014). Effectiveness of the tailored Evidence Based Practice training program for Filipino physical therapists: A randomized controlled trial. BMC Medical Education, 14(1). doi:10.1186/1472-6920-14-147. 
13. Mcevoy, M. P., Williams, M. T., \& Olds, T. S. (2010). Evidence based practice profiles: Differences among allied health professions. BMC Medical Education, 10(1). doi:10.1186/1472-6920-10-69.

14. Mcdonald, S., Turner, T., Chamberlain, C., Lumbiganon, P., Thinkhamrop, J., Festin, M. R., . . . Green, S. (2010). Building capacity for evidence generation, synthesis and implementation to improve the care of mothers and babies in South East Asia: Methods and design of the SEAORCHID Project using a logical framework approach. BMC Medical Research Methodology, 10(1). doi:10.1186/1471-2288-10-61.

15. Lizarondo, L. M., GrimmerSomers, K., Kumar, S., \& Crockett, A. (2012). Does journal club membership improve research evidence uptake in different allied health disciplines: A pre-post study. BMC Research Notes, 5(1), 1. doi:10.1186/1756-0500-5-588.
16. Mcleod, R. S., Macrae, H. M., Mckenzie, M. E., Victor, J. C., \& Brasel, K. J. (2010). A Moderated Journal Club Is More Effective than an Internet Journal Club in Teaching Critical Appraisal Skills: Results of a Multicenter Randomized Controlled Trial. Journal of the American College of Surgeons, 211(6), 769-776. doi:10.1016/j.jamcollsurg.2010.08.01 6.

17. Honey, C. P., \& Baker, J. A. (2011). Exploring the impact of journal clubs: A systematic review. Nurse Education Today, 31(8), 825-831. doi:10. 1016/ j.nedt. 2010.12.020.

18. Ahmadi, N., Mckenzie, M. E., Maclean, A., Brown, C. J., Mastracci, T., \& Mcleod, R. S. (2012). Teaching Evidence Based Medicine to Surgery Residents-Is Journal Club the Best Format? A Systematic Review of the Literature. Journal of Surgical Education, 69(1), 91-100. doi:10.1016/j.jsurg. 2011.07.004. 